\title{
O que move a luta? A Maré Verde Argentina e a resistência das mulheres do/no Sul Global
}

\author{
What moves the fight? Argentina's green tide and the resistance of women from/in the Global South
}

DOI: https://doi.org/10.22456/2178-8839.113901

Livian Lino Netto

Universidade Federal de Pelotas, Pelotas, Brasil

livianlino@gmail.com

Isadora Ebersol

Universidade Federal de Pelotas, Pelotas, Brasil

isadora.ebersol@gmail.com

Julia Rocha Clasen

Universidade Federal de Pelotas, Pelotas, Brasil

clasenjulia1@gmail.com

\section{Resumo}

Neste trabalho propomos refletir a Maré Verde como expressão de um marcante momento na história do movimento feminista internacional, que aconteceu na Argentina, no dia 30 de dezembro de 2020. Neste dia, com 38 votos a favor, 29 contra e uma abstenção, o senado argentino aprovou a lei que permite que a interrupção voluntária da gravidez seja realizada de maneira legal, segura e gratuita para mulheres até a 14 a semana de gestação. Ao propor uma reflexão a partir da análise de conjuntura produzida sobre esse momento, não nos referimos somente a vitória institucional que isso representa, enquanto direito social historicamente reivindicado, mas sobre a sua construção enquanto parte de um conjunto de pautas políticas de uma resistência que não se encerra naquele momento, mas sua vitória potencializa um conflito político historicamente travado pelas mulheres do Sul Global. Neste trabalho concluímos que a ação política travada pelas mulheres argentinas reflete na articulação do movimento feminista na América Latina e no denominado Sul Global, como expressão de uma reivindicação de caráter histórico conflitivo da sua resistência.

Palavras-chave: Luta; Movimento de mulheres; Sul Global; Maré Verde; Argentina;

\begin{abstract}
In this paper, we propose to reflect Green Tide as an expression of a remarkable moment in the history of the international feminist movement, which took place in Argentina, on December 30, 2020. On this day, with 38 votes in favor, 29 against, and one abstention, the Argen tine Senate approved the law that allows the voluntary termination of pregnancy to be carried out legally, safely and free of charge for women until the 14th week of gestation. In proposing a reflection by proposing a reflection based on the analysis of the situation produced about on this moment, we are not only referring to the institutional victory that this represents, as a social right historically claimed, but about its construction as part of a set of political guidelines of a resistance that does not end at that moment, butits victory enhances a political conflict historically fought by women in the Global South. We concluded with this work that the political action carried out by Argentine women reflects on the articulation of the feminist movement in Latin America and the so-called Global South, as an expression of a claim of a conflicting historical character of their resistance.
\end{abstract}

Keywords: Fight; Women's movement; Global South; Green Tide; Argentina; 


\section{Introdução}

Maré, substantivo feminino. Caracteriza o movimento periódico das águas do mar, suas subidas e descidas. Maré, substantivo feminino. Designa também algo em grande quantidade, uma multidão. Maréé também uma força, uma tensão exercida sobre algo ou alguém e que estimula comportamentos, ações. Maré: movimento cíclico, assim como o são os movimentos feministas e de mulheres na América Latina, em enfoque aqui, na Argentina.

No dia 30 de dezembro de 2020 uma maré verde inundou as calles argentinas exigindo "educação sexual para decidir, anticoncepcional para não abortar e aborto legal para não morrer”. Este não foi o único dia em que a multidão ocupou as ruas, mas foi o marco de um acumulado de lutas e de um longo processo de organizações de mulheres em torno da pauta de legalização do aborto. Neste dia, com 38 votos a favor, 29 contra e uma abstenção, o senado argentino aprovou a lei que garante que o procedimento seja realizado de maneira legal, segura e gratuita para mulheres até a $14^{\mathrm{a}}$ semana de gestação. Veículos de comunicação de todo o mundo noticiaram a conquista de corrente de uma trajetória acumulada de luta das mulheres argentinas e que, pela intensa capacidade de politização do movimento e do debate público que o tema gerou, abriu horizontes e aspirações de luta para outros movimentos de mulheres do Sul Global.

A América Latina é um dos continentes com maiores punições para quem pratica o aborto, sejam estas de caráter institucional/criminal, de caráter moral, social, religioso ou simbólico. Mesmo em situações nas quais ele é permitido por lei, considerando as particularidades da legislação de cada país, como em casos de gestação decorrente de estupro, gestações de fetos anencéfalos ou para proteger a vida da mulher, estas não estão livres de sansões, coerções e impedimentos.

Podemos refletir a partir do caso de Vicenta Avendaño, moradora da periferia de Buenos Aires, que foi emblemático neste sentido. Em 2006, Vicenta descobriu que sua filha, portadora de deficiência intelectual, havia engravidado após ser abusada sexualmente por um homem de sua família. Amparada legalmente pelo artigo 86, inciso $1 \mathrm{e}$ 2 do código penal argentino de 1921, que permite o aborto a fim de evitar perigo de vida ou de saúde para a mulher ou se a gravidez é decorrente de violação sexual de mulher com deficiência mental, Vicenta, no entanto, precisou travar uma batalha judicial com ampla divulgação midiática, chegando à Suprema Corte do país, a fim de conseguir autorização do Estado para a realização do procedimento, o que não ocorreu. Mãe e filha encontraram apoio em grupos feministas e de mulheres ativistas que viabilizaram a interrupção da gravidez de forma clandestina após a negativa judicial e processaram internacionalmente o Estado argentino pela condução do caso junto ao Comitê de Direitos Humanos da ONU. Em 2011, a ONU condenou o Estado Argentino por violar o direito do aborto legal à filha de Vicenta (DÍAZ, 2015).

Recentemente, em 2020, foilançado o documentário de animação que leva o seu nome, dirigido por Dario Doria ${ }^{1}$, que conta a trajetória de ambas. O contexto de extrema vulnerabilidade em que mãe e filha se encontramé potencializador da violência institucional, jurídica, médica e religiosa que acomete diariamente os corpos e a autonomia de mulheres. A menina sofre então, uma dupla violência misógina: o abuso sexual produto da cultura patriarcal e a violência moral, física e psicológica infringida pelo poder público, que deveria defendê-la. É apenas pela luta organizada das mulheres que a menina passa a existir enquanto sujeita portadora de direitos humanos básicos.

No Brasil em 2020, outro caso de gestação decorrente de estupro de vulnerável, desta vez de uma menina de 10 anos de idade no Espírito Santo, é representativo de como esta punição funciona de forma nefasta contra o corpo e a moral da mulher. Num primeiro momento impedida no hospital de realizar a interrupção da gravidez que, segundo a equipe médica local havia passado da idade gestacional amparada por lei, a menina finalmente teve o procedimento autorizado pela justiça. Mais grave, no entanto, foi a divulgação ilegal, por parte de uma militante de grupos de direita, de dados sigilosos como o nome da menina e endereço de onde ela se encontrava, a fim de mobilizar manifestações contra a 
realização do procedimento ${ }^{2}$. Grupos religiosos, autodenominados pró-vida, e até mesmo parlamentares se uniram para protestar em frente ao hospital. Além de violaros direitos fundamentais da menor, a censura pública à vítima e aos médicos que realizariam a interrupção tem caráter de coerção social e acabam, por fim, desestimulando a denún cia de casos de abuso e violação sexual, motivando a continuidade de gestações não desejadas e/ou perigosas, bem como a realização abortos clandestinos e inseguros, com alto risco para a vida de mulheres. Esses são casos nevrálgicos, embora longe de serem os únicos, de como agem as autoridades e alguns setores da sociedade diante da possibilidade de decisão das mulheres sobre o seu corpo.

Se mesmo dentro dos limites da legalidade casos como este seguem acontecendo é porque essa é uma situação que evidencia a precariedade do apoio institucional à mulherque decide pela interrupção da gravidez. Para além da política institucional, a realidade é que a prática social e médica desestimula e dificulta a interrupção, seja por desconhecimento da legislação, por crenças pessoais dos membros da equipe médica e de autoridades ou até mesmo por pressãosocial aos médicos ou às mulheres.

A criminalização e deslegitimação social da mulher na decisão pela interrupção da gravidez se expressa de forma tão cruel que independente das condições que precise enfrentar, decidir sobre a continuidade ou não da gestação nem mesmo parece ser uma opção. Ao refletir acerca dessa temática, não estamos falando de uma condição individual de decisão, mas como direitos são historicamente retirados das mulheres e de outros atores sociais, que sequer podem cogitar sobre eles como alternativa.

Assim, o objetivo deste textoé refletir acerca da luta das mulheres pelo direito e autonomia do próprio corpo e a favor da legalização e descriminalização do aborto tendo o caso argentino como foco. Tal reflexão é realizada a partir da análise de conjuntura (SOUZA, 2005) realizada com base nas ações das feministas argentinas que conseguem transcender a política conservadora do seu país e conquistam o direito ao aborto legal fazendo com que, sua luta se expanda para além do continente Sul americano, internacionalizando sua articulação em torno das pautas do movimento, sem perder sua força política. O eixo principal de análise reside na consciência da simbiose entre patriarcado-racismo-capitalismo como três estruturas de dominação-exploração indissociáveis e sedimentadas na cultura colonial/moderna e que determinam as particularidades da condiçãovivida pelas mulheres latino-americanas, bem como as estratégias de luta dos movimentos feministas e de mulheres produzidos a partir do Sul Global.

Ao pensarmos os movimentos feministas no/do Sul Global pontuamos o olhar histórico que conduz essa análise sociopolítica, uma vez que, ao falarmos dos movimentos sociais e da luta das mulheres na América Latina, nos referimos à construção de um formato de resistência que é essencialmente distinto das ações políticas nos países dominantes. Nesse sentido nos encontramos nessa reflexão com uma tentativa teórica e epistemológica de pensar os formatos de ação coletiva no contextolatino-americano na era contemporânea, ou seja, suas especificidades diante dos formatos de associativismo dos novos movimentos sociais no contexto latino-americano. Como Maria Glória Gohn (1997) coloca, pensar um paradigma teóricolatino-americano dos movimentos sociais é uma questão estratégica, pois não se trata simplesmente de um paradigma teórico, mas, mais que isso, de diferenciar as lutas e os movimentos sociais latino-americanos dos movimentos europeus, norte-americanos, canadenses etc. E, portanto, reconhecer um formato de luta que é historicamente constituído e distorcido pelas relações de poder hegemônicas.

Ao referenciar esse caráter histórico da luta, estamos também considerando a construção de um olhar reflexivo acerca do movimento das mulheres no período recente. Esse formato de resistência vem acompanhado de marcadores sociais próprios do contexto sob o qual é analisado, apresentando, assim, diferenças em seus formatos de organização, projetos políticos, propostas com as ações e articulação da luta que parte do reconhecimento de contradições compartilhadas (GOHN,1997).

\footnotetext{
2 Sara Giromini, conhecida no Brasil como ex-feminista e atualmente extremista de movimentos de direita no país, divulga dados sobre o aborto a ser realizado na menina de 10 anos, fazendo com que manifestantes se reúnam no local a fim de protestar contra a realização do procedimento (BBC, 2020).
} 
É importante salientar que quando falamos em movimentos feministas latino-americanos não pretendemos evocar uma homogeneidade para construções históricas tão complexas e diversas e que, muitas vezes, fogem à conceituação teórica universalista. O que se pretende é contribuir com uma geopolitização do debate feminista, com enfoque no contextolatino-americano, pois como aponta Luciana Ballestrin:

As características compartilhadas pela América Latina, Centro-América e Caribe como região não implicam uma vivência e um passado comumente sentidos por todas as mulheres "latino-americanas". Aqui estamos falando de desigualdades e injustiças, amarradas historicamente em estruturas políticas, sociais, culturais e econômicas, para pensarmos as múltiplas identidades, necessidades, reivindicações e interesses feministas. (BALLESTRIN, 2017, p. 1050)

Neste sentido, para pensar os movimentos de mulheres, como os que acontecem na Argentina e que se internacionalizam em marés mundiais de reinvindicação e luta feminista, é preciso refletirmos sobre o sentido da luta feminista e sua internacionalização enquanto movimento potente de transformação radical do mundo.

\section{O que é luta? Uma perspectiva feminista}

Mas, o que éluta? Historicamente, as sociedades foram construídas e organizadas de tal forma que a luta faz parte da vida das pessoas, mesmo que o seu significado e sua presença não sejam óbvios. Boaventura de Sousa Santos (2017) compreende como "luta toda a disputa ou conflito sobre um recurso escasso que confere poder a quemo detém" (SANTOS, 2017).

Para discutir a respeito do que são as lutas, é preciso compreender que elas se dão além da ciência e da epistemologia, mas que seu sentido, significados e alvos podem ser institucionalizados e apropriados por organizações que impõe a partir de fora os seus saberes, discursos e práticas, ignorando a experiência concreta dos agentes e grupos sociais que vivenciam a luta. Ao se apropriarem das pautas dos movimentos, assumem assim, o papel de protagonistas no combate à dominação, mesmo que acabem, muitas vezes, sendo também agentes dessa mesma dominação. Boaventura de Sousa Santos (2019) chama esse tipo de organização de “ONGzação” das lutas, processo que, na maioria das vezes, faz uso de uma linguagem distante da experiência concreta dos/das oprimidos/oprimidas e abrevia os movimentos, oferecendo "pacotes de slogans e de pseudossoluções" (SANTOS, 2019, p. 105) com o objetivo de "apresentar como libertação ou emancipação aquilo que acaba por ser uma maior dependência dos oprimidos [das oprimidas] face às agendas hegemônicas das organizações” (SANTOS, 2019, p.105).

A “onguização” do movimento feminista, segundo Ballestrin (2017), vem sendo o resultado de sua crescente transnacionalização e internacionalização, processo que, segundo a autora, pode ser criticado pelo protagonismo do Norte em aplicar de forma verticalizada suas agendas no Sul. Como resultado, "Seu associativismo ativista pode ser extremamente elitizado e profissionalizado" (BALLESTRIN, 2017, p. 1050), o que de fato produz uma certa desterritorialização do campo ativista, que se vê mais fragmentado e distante das bases materiais da luta.

A “onguização” presente nos movimentos sociais e a institucionalização da luta é marcador presente na sua construção, como estratégia política do Estado de conter a resistência. Como coloca Maria Glória Gohn (1997), “a cada onda de movimentos surgem uma série de leis e novos órgãos públicos para cuidar da problemática” (GOHN,1997,p.234). Essa tentativa de institucionalização da luta e apaziguamento do conflito político intensifica a descrença política presente na população, como fator elementar na construção histórica latino-americana, marcada pela distorção da identidade e memória dos povos.

Na mesma esteira, um outro processo vem sendo marcante no feminismo, em especial o feminismo desenvolvido no chamado Norte Global apoiado em um pensamento de viés liberal, quando muitas de suas bandeiras são cooptadas por grandes corporações e instrumentalizadas a serviço do capital. O discurso do empoderamento, incorporado de forma eficaz pela indústria da moda e dos cosméticos, é um exemplo bem sucedido dessa prática quando, por trás doverniz do discurso 
emancipatório, não só não rompe com as principais formas de dominação feminina, como reproduz em seu cerne as opressões de gênero, raça e classe. Nancy Fraser (2009), ao analisar a subordinação da crítica radical do feminis mo de segunda onda à agenda neoliberal, chama atenção para o sucesso que o movimento teve em modificar a cultura e as mentalidades em contraste ao fracasso em modificar as estruturas institucionais e o quanto as próprias mudanças culturais impulsionadas pela segunda onda do feminismo, legítimas em sua origem, "serviram para legitimar uma transformação estrutural da sociedade capitalista que avança diretamente contra as visões feministas de uma sociedade justa.” (FRASER, 2009, p.14)

As lutas sociais sempre existiram e,para Karl Marx e Friedrich Engels estão presentes na sociedade até hoje, afinal, “a história de todas as sociedades até agora tem sido a história das lutas de classe.” (MARX; ENGELS, 2008. p.10). Mas as lutas não se restringem somente às lutas de classenem obedecem necessariamente à lógica subjacente ao marxismoe ao socialismo europeu, como principal base epistemológica. Há outras formas de luta que são protagonizadas por outras/outros atores políticos e que se agrupam em torno de outras categorias ou marcadores sociais além da classe, como o sexo, o gênero e a raça, por exemplo, alargando assim a ideia marxista do que são as lutas sociais e de como se constituem. Segundo Heleieth Saffioti (1987), que estabelece uma crítica à priorização apenas da luta de classes frente às demais, a democracia verdadeira só pode acontecerquando há a destruição do trio patriarcado-racismo-capitalismo e a consciência da simbiose entre estas três estruturas de dominação-exploração "muda inteiramente a estratégia de luta das classes trabalhadoras" (SAFFIOTTI, 1987, p. 94).

O que significa lutar contra a dominação do capitalismo, colonialismo e patriarcado? E mais,

Como separar o patriarcado, o racismo e o capitalismo se, na prática, na realidade cotidiana, na luta diária pela sobrevivência, não é possível distinguir como independentes, capazes de atuação autônoma, estes três sistemas de dominação-exploração que se fundiram ao longo da história? (SAFFIOTTI, 1987, p. 88).

Ao nos perguntarmos sobre isso, precisamos pensar sobre como funcionam as estruturas de dominação/exploração para que então se construam as lutas. Silvia Federici demonstra,em Calibã e a bruxa: mulheres, corpo e acumulação primitiva (2017), que no período feudal as mulheres tiveram grande importância nas lutas campesinas em toda a Europa, lutas estas que puseram em xeque a capacidade de acumulação de riquezas desse tipo de sociedade.

De alguma forma, o capitalismo nasce como resposta (opressiva) a essas lutas, principalmente quando, para que possa se desenvolver, desvaloriza sistematicamente o trabalho da mulher e apropria -se do seu corpo para a reprodução da força de trabalho, ou seja, para gerar trabalhadores para essa nova forma de organização do trabalho e das riquezas.

Nesse sentido, portanto "forçar as mulheres a procriar contra a sua vontade ou, como dizia uma canção feminista dos anos 1970, forçá-las a 'produzir filhas e filhos para o Estado’3 é uma definição parcial das funções das mulheres na nova divisão sexual do trabalho” (FEDERICI, 2017, p. 182). É parte constituinte do desenvolvimento capitalista (junto aos processos de expansão colonial e de expropriação e privatização das terras), não só o controle dos corpos das mulheres, dos conhecimentos femininos sobre contracepção passados de geração em geração, como a criminalização de qualquer controle da mulher sobre a procriação.

Um processo complementar, segundo Federici, é a desvalorização do trabalho feminino e a transformação das mulheres em não trabalhadoras, segundo o novo modelo capitalista, um processo que "estava praticamente completo até o final do século XVII" (FEDERICI, 2017, 182). As mulheres foram, assim, encerradas no trabalho doméstico, não porque não são produtoras, mas porque toda atividade praticada por elas, m esmo que diretamente ligada à produção de bens, era chamada de "trabalho doméstico" e considerada não produtiva, enquanto a mesma atividade praticada por homens era considerada produtiva.

\footnotetext{
3 Canção feminista italiana de 1971, intitulada "Aborto di stado" (Aborto de Estado). Faz parte do álbum Canti de donne in lotta (Canções de mulheres em luta), lançado em 1974 pelo grupo musical do Comitê por um salário para o trabalho doméstico, da cidade de Pádua, Itália. (FEDERICI, 2017. p.182).
} 
A exclusão das mulheres das relações produtivas e do trabalho socialmente reconhecido e remunerado está intimamente ligada à imposição da maternidade e à "redefinição da família como lugar para a produção da força de trabalho" (FEDERICI, 2017, p. 188), bem como nas relações de dominação/exploração que os homens e o Estado estabelecem com relação às mulheres e seus corpos. A pobreza passa então a ser feminilizada e a família nuclear passa a ser uma das principais instituições de controle feminino.

$\mathrm{Na}$ análise do contexto de desenvolvimento do capitalismo de Federici, as mul heres seriam as grandes substitutas das terras perdidas pelos homens no processo de expropriação e privatização, de modo que deveriam dar aos homens livre acesso a seus corpos, ao seu trabalho não-remunerado e ao trabalho dos filhos gerados e cuidados por elas: "o trabalho das mulheres começou a se parecer com um recurso natural, disponível para todos, assim como o ar que respiramos e a água que bebemos” (FEDERICI, 2017, p.191).

Foi com a expansão do domínio colonial, em especial das Américas, que o capit alismo pôde "consolidar-se e obter predominância mundial, tornando-se precisamente o eixo em torno do qual todas as demais formas foram articuladas para os fins do mercado mundial” (QUIJANO, 2005, p. 115). A América foi, segundo Aníbal Quijano o primeiro espaço/tempo de um novo padrão de poder mundial. Além de demonstrar a íntima ligação entre colonialismo e capitalismo de modo que um não possa ser pensado sem o outro, a modernidade, para além da ideia de progresso, também esconde a colonialidade como seu lado obscuro, como demonstra Walter Mignolo (2017).

Quijano parte dessa indissociabilidade para desenvolver o conceito que chama de "colonialidade do poder" (QUIJANO, 2005). Este conceito é utilizado para pensar a continuidade, atualização e contemporizaçã o de estratégias de poder produzidas pela colonização dentro das estruturas do sistema -mundo capitalista moderno mesmo após o fim do período colonial nas Américas (BALLESTRIN, 2013).

A classificação da população mundial em torno da ideia de raça é, para Quijano (2005), um dos eixos centrais da colonialidade do poder e expressa a experiência básica tanto quanto durável da dominação colonial. Assim, a colonialidade como um dos elementos constitutivos e específicos do padrão mundial do poder capitalista sustenta-se na imposição de uma classificação racial/étnica da população do mundo. O colonialismo é mais antigo, a colonialidade mais duradoura, profunda e resultado do primeiro(QUIJANO, 2009):

Assim, no controle do trabalho, de seus recursos e de seus produtos, está a empresa capitalista; no controle do sexo, de seus recursos e produtos, a família burguesa; no controle da autoridade, seus recursos e produtos, o Estado-nação; no controle da intersubjetividade, o eurocentrismo. Três, cada uma dessas instituições existe em relações de interdependência com cada uma das outras. Por isso o padrão de poder está configurado como um sistema (QUIJANO, 2005, p. 113).

A dimensão colonial define novas "formas de guerra" (SEGATO, 2014), caracterizadas pela informalidadee define novos modos de violência que tem como alvo o corpo das mulheres, e deforma ainda mais acentuada, das mulheres pobres e racializadas pela intersecção das diversas formas de dominação/exploração. Existe uma reconceitualização da violência machista e neoliberal que é essencial para o movimento feminista dos últimos anos. O corpo das mulheres está em jogo e, segundo Silvia Federici (2017), existe uma guerra permanente contra as mulheres na qual o ponto comum é a desvalorização da vida e do trabalho impulsionada pela globalização.

É como se o poder colonial fosse somado ao poder patriarcal; a violência sexual em particular aparece como fundamental para entendermos a violência colonial em geral. O corpo feminino pode ser pensado como o primeiro "território" a ser conquistado e ocupado pelo colonizador (homem, branco, cristão, europeu e heterossexual). Nas mais diversas situações de conflitualidades violentas, a vulnerabilidade do corpo feminino é acentuada" (BALLESTRIN, 2017, p.1038).

Compreendemos que tanto os corpos coletivos como os individuais são corpos sociais, já que além do físico, são um conjunto de repertórios comportamentais, são territórios de lutas e de disputas, carregando as marcas desse processo, 
especialmente os corpos das mulheres que foram (e são) apropriados como territórios de dominação. Nesse sentido e a partir do cenário atual de avanço neoliberal contra o corpo das mulheres, da apropriação da sua capacidade produtiva e da cooptação das pautas feministas pelo discurso liberal que realizamos, neste ensaio, uma análise de conjuntura do movimento que ficou conhecido como Maré Verde.

A análise de conjuntura é aqui entendida como a capacidade de considerar variáveis políticas, econômicas, culturais, pensando a partir de acontecimentos, atores, cenários, relações de força e articulação entre estrutura e conjuntura (SOUZA, 2005). Desse modo, é possível fazer uma leitura da atuação política e da organização das mulheres a partir das greves feministas que, ao transcender as fronteiras e entenderem o seu corpo como território, reverberam ao redor do mundo.

\section{A Maré verde e a internacionalização da luta feminista}

\footnotetext{
"Estamos aqui porque outras caminharam antes e porque outras vão caminhar depois. Penso que não é apenas a revolução das filhas, esta é a revolução também das nossas mães e das nossas avós. O movimento de mulheres nos interpela a construir essa transversalidade" (Anabel Fernández Sagasti, senadora argentina) $)^{4}$
}

Desde março de 2015 o coletivo Ni Una $\operatorname{Menos}^{5}$ convoca mulheres na Argentina e na/da América Latina para manifestações contra a violência sexual e de gênero e em outubro de 2016, com o assassinato de Lucia Pérez (PARDO, 2016) ${ }^{6}$ na Argentina, um grande chamado foi realizado para uma greve: Nosotras paramos ${ }^{7}$. Inicia-se o movimento de greve de mulheres convocado para o dia 8 de março de 2017. Esta greve não foi um evento isolado. Vem sendo construída em um processo que continua aberto e se converteu em uma ferramenta capaz de impulsionar internacionalmente o m ovimento feminista de maneira inédita. Transforma a mobilização contra os feminicídios em um movimento radical, massivo e capaz de politizar de forma inovadora a aversão às violências (GAGO, 2020).

Para Valentina Avelluto (2019) a primeira marcha do Ni Una Menos funcionou como um "batismo das ruas" que estabeleceu um antes e um depois na história recente da Argentina, diante da necessidade de mobilizar as múltiplas forças sociais contra o contexto neoliberal em curso. Silvana Sciortino (2018) considera essa ocasião como o início de um novo "momento de abertura" do movimento amplo de mulheres e de reconfiguração, diante do cenário político-social presente, de reivindicações, lutas e organizações já existentes. Esse movimento funciona como uma situação refunda cional da historiografia de lutas feministas argentinas. Assim como destaca Maria Alice Gutiérrez (2019), é necessário compreender que, antes de serem movimentos espontâneos, os movimentos feministas recentes da Argentina têm uma longa história pregressa que os fortaleceu. São produtos de um caminhar coletivo subterrâneo gestado "de modo rizomático no conjunto do país, regionalmente e a nível global através dos anos” (GUTIÉRREZ, 2019, p. 36, tradução nossa ${ }^{8}$ ), principalmente através dos Encontros Nacionais de Mulheres que ocorrem na Argentina desde 1980 e foram, para Gutiérrez, escolas de formaçãopolítica.

Nesse mesmo sentido, Avelluto (2019) reforça a necessidade de desenterrar esse fio condutor de uma tradição de lutas com as quais se possa apoiar e fortalecer o presente, principalmente para compreender que não se parte do zero na construção do que entende como "momento-processo" de produção política e ideológica. A massividade e potência dos movimentos recentes, longe de serem espontâneas, são produto de um trabalho silencioso (e silenciado) de longa data,

\footnotetext{
${ }^{4}$ Fala de senadora argentina após a aprovação da lei que legaliza o aborto no país.

${ }^{5}$ Coletivo de mulheres argentinas.

${ }^{6}$ Jovem argentina morta vítima de violência sexual e de gênero, no ano de 2016 por dois homens.

${ }^{7}$ Referente ao manifesto das greves feministas promovidas pelo Coletivo Ni una a menos.

${ }^{8}$ No original “[...] de modo rizomático en el conjunto del país, la región y a nivel global a través de los años."
} 
como uma força subterrânea que estabeleceu alianças, estratégias, consensos, práticas e teorias e que hoje rompe o silêncio na força dos encontros e na potência das ruas (AVELLUTO, 2019).

É necessário que se reconheça esselegado subjacente aos movimentos recentes para que se possa delinear seus múltiplos significados e sua capacidade de internacionalização. Sobre isso, Gutiérrez destaca a múltipla significação dos lenços (pañuelos) verdes como estratégia de luta surgida através da Campaña $28 \mathrm{~S}$ pela Descriminalização do Aborto na América Latina e Caribe e que a nível local, regional e global se converteu em grandes "pañuelazos" como uma forma performativa do corpo político ocupar o espaço público e disputar os sentidos da luta. Os lenços verdes, que se tornaram símbolo da Campanha Nacional pelo Direito ao Aborto Legal, Seguro e Gratuito, identificam a maré como um só corpo e são o elo intergeracional que reorganiza as lutas femininas na Argentina "onde a mistura de experiências passadas e realidades presentes produzem uma sinergia extremamente produtiva” (GUTIÉRREZ, 2019, p. 36, tradução nossa ${ }^{9}$ ). Trazem ao centro a representação dos lenços brancos usados pelas Mães e Avós da Praça de Maio, organizações de mulheres que atuam desde a época da ditadura militar argentina buscando ativamente informações sobre os filhos e netos desaparecidos durante o regime militar e pressionando pela responsabilização dos culpados.

Esse impulso intergeracional e intercultural, que soma cada vez mais grupos subalternos em torno de consensos comuns, é parte do "momento de abertura" de que trata Sciortino (2018). Essa abertura configura o movimento amplo de mulheres na Argentina como um ator político dinâmico constituído a partir da diversidade e da continuidade histórica que hoje possibilita e fortalece os encontros massivos de mulheres de diferentes setores, origens e com distintas trajetórias e pertencimentos.

O feminismo, como uma política que compreende o corpo como território, diz aos legisladores do mundo capitalista, colonial e patriarcal que não nos representam. Fora todos! As mulheres não aceitam que a política tradicional continue a confinar seus corpos na esfera doméstica. Ao vetar a legislação do aborto, estão sancionand o o poder masculino sobre o corpo das mulheres. Ao tomar as ruas e colori-las deverde, as mulheres evidenciam as categorias público e privado. O corpo território que ocupa as calles diz: não nos submeteremos à invisibilidade, não nos resignaremos no silên cio, não nos acomodaremos e não seremos mais uma parte tutelada da democracia capitalista (GAGO, 2020).

Das greves feministas emerge um novo horizonte de organização. Manifestam a precariedade como condição comum, porém diferenciada por questões de gênero, de raça e de classe. Tornam-se umaferramenta que pode ser capaz de entender a violência como uma das formas de exploração do capitalismo. Assim, apresentam alternativas para o modelo que está posto e que surge especialmente da luta das mulheres do/no Sul Global. Elas constroem outras práticas de organização e de luta constituindo novas alternativas aos problemas gerados pelas relações coloniais e para as imaginações emancipatórias elaboradas neste contexto como alternativa para este mundo. Pode -se pensar como uma resposta das minorias ativas protagonizadas por mulheres, como alternativa radical de transformação.

É diante desse contexto neoliberal, da violência de gênero, do trabalho invisibilizado das mulheres que as greves feministas surgem como um dispositivo. Estas transformam a mobilização contra as violências em um movimento radical, massivo e politizador. São capazes de conectar e cruzar as violências machistas e econômicas e tecem uma alternativa feminista colocando o movimento em situação de luta, a fim de romper com estruturas que possibilitam a valorização do capital.

As greves feministas são um instrumento político de insubordinação ao capitalismo neoliberal que produz violências. Articulam gênero, raça e classe em uma abordagem multidimensional que cria ecossistemas de conexões. Essa abordagem coloca em evidência as redes de opressão concretas e subjetivas que tecem as teias da opressão e das discriminações (VERGÈS, 2020). Neste sentido, as greves feministas do/no Sul Global buscam denunciar e combater todas as formas de opressão a fim de que a libertação das mulheres dos sistemas de dominação seja a libertação de todas as pessoas das amarras coloniais de saber e de poder.

${ }^{9}$ No original: "[...] donde la mixtura de las experiencias pasadas y las realidades presentes producen una sinergía extremadamente productiva" 
A greve pode ser um dispositivo de recuperação da narrativa militante radical.É preciso superar o feminismo civilizatório que apazigua figuras radicais como, por exemplo, a de Angela Davis, fazendo com que se construam movimentos feministas bem comportados e aceitáveis.

Queremos pôr em prática um pensamento utópico, entendido como energia e força de insurreição, como presença e como convite para sonhos emancipatórios, como gesto de ruptura: ousar pensar para além do que se apresenta como "natural", "pragmático", "razoável". Não queremos construir uma comunidade utópica, mas restaurar toda a sua força criativa em sonhos de insubmissão e resistência, justiça e liberdade, felicidade e bondade, amizade e encantamento. (VERGÈS, 2020, p.136)

No caso das greves das mulheres, este grupo pode ser considerado uma minoria, não no sentido quantitativo, mas em relação à maioria hegemônica. Neste caso, homens brancos, cisgêneros, ricos, heterossexuais, cristãos e que controlam, por exemplo, os corpos das mulheres através de políticas públicas, impedindo a legalização do aborto que, no caso do Brasil, passa ainda por uma bancada evangélica.

A Greve Internacional das Mulheres, denominada também como Paro Internacional de Mujeres (PIM) e International Women's Strike (IWS), aconteceu em 55 países e é a partir das lutas feministas na/da América Latina que as palavras de ordem “nem uma a menos” foram traduzidas e utilizadas em diversoslugares do mundo. Diante da paralisação dos trabalhos das mulheres em um sentido produtivo e reprodutivo foi demonstrado que o mundo só se reproduz a partir do trabalho não remunerado pelo capital que é exercido pelas mulheres. O propósito era parar as atividades que contribuem para a opressão das mulheres e, também, produzir as atividades que ampliam o futuro do que queremos como sociedade (FEDERICI, 2021).

A novidade do movimento feminista nos últimos anos é a de ter sido convertido em um fenômeno mundial. Ele emerge doSul, expande e alimenta um internacionalismo de massas e, ao estarterritorializado em cadalugar, em cada luta específica, produz vínculos que ecoam e se alimentam das dimensões concretas destas lutas. Assim, praticam modos de conectar os conflitos em uma perspectiva dos feminismos sem fronteira, a partir de um diagnóstico das contraofensivas que excedem marcos estatal-nacionais (GAGO, 2020). Esse movimento cria uma força que aparece nas dinâmicas organizativas de cada espaço e que conectam e se expandem nas organizações das greves internacionais, em uma trama de lutas que se encontram e se potencializam.

Assim, quando pensamos na resistência das mulheres a partir de uma leitura do/no Sul Global, nos referimos também a um formato de resistência, que reivindica não apenas pautas conjunturais, mas uma luta de reivindicação da sua história e da sua narrativa. O que torna acertado quando pensamos a contestação das mulhereslatino-americanas com a sua luta, correspondente a uma exigência sobre o direito dos seus corpos, mas também, e mais que isso, sobre o direito de ir às ruas e reclamar uma outra existência e condições de requerer a sua atuação social. Uma reivindicação de si, e de uma história que lhe é ocultada e negada.

Não por acaso essa luta não se encerra na Argentina, nem mesmo tem uma data demarcada, mas se localiza em um período que abarca um conjunto de pautas do movimento feministaque se articulam internacionalmente. Toma conta da América Latina e se expressa em uma resistência que não se demonstra finalizada,mas toma fôlego conforme o sentido da luta e as exigências políticas também se estabelecem. A internacionalização praticada pelo movimento feminista qualifica cada situação de luta concreta: a torna mais rica, amplia a imaginação política e, ao mesmo tempo, cria uma onipresença, e é assim que podemos dizer: estamos em todos os lugares. 


\section{Considerações finais: de e para o Sul Global, as mulheres se levantam}

o que se mobiliza com a maré verde é justamente uma dinâmica intergeracional que vem tramando, aprofundando e organizando laboriosamente o desejo de autonomia sobre nossos corpos e territórios. Mas, acima de tudo, nossa vitória será a confirmação de que a luta coletiva a que os feminismos estão colocando nossos corpos, e nisso reinventando nosso corpo comum, está pronta para mudar tudo (Laboratoria - Espacios de investigación Feminista).

Uma das alternativas propostas pelas mulheres do Sul Global, em especial as mulheres na Argentina,é a luta pela legalização do aborto. Essa luta supera os limites do corpo individual e do território da lei. Converteram a luta em uma discussão pública de argumentação, confrontação e exibição, conseguindo impor à agenda midiática uma discussão que fez transbordar a disputa pelo terreno social, expandindo-o em uma Maré Verde que inundou escolas, favelas, sindicatos e praças. Essa conjunção entre a dinâmica da greve e a Maré Verde relacionou os diferentes modos de luta contra a exploração dos corpos das mulheres (GAGO, 2020).

Na Argentina, a Campanha Nacional pelo Direito ao Aborto Legal, Seguro e Gratuito possui mais de 500 grupos e foi fundada em 2005, no Encontro Nacional de Mulheres. Foi nesse momento que surgiu o lenço verde que foi transformado no símbolo da luta que se internacionaliza. O lenço verde torna-se um símbolo de identificação de continuidade da luta das argentinas, homenageando as mães e avós da Plaza de Mayo, mas ampliando o significado da luta: o direito de decidir sobre os próprios corpos. A maré verde se torna um único corpo coletivo que vai às ruas compreendendo que, se somos atacadas, não é possível ficar passiva diante das violências cotidianas. Ao ir para o enfrentamento, o corpo individual se torna coletivo e território de disputa. Foram as lutas que inventaram a ideia de corpo-território, um conceito político que evidencia a exploração (GAGO, 2020).

Não restrito a Argentina, a luta das mulheres se expressa em uma internacionalização da resistência que ganha repercussão em toda América Latina, a partir de contradições compartilhadas, que não se encerram em um local, mas são historicamente determinadas e delimitam a vivência das mulheres em contextos distintos, enquanto uma construção política marcada pela opressão e exploração. Ainda que não caiba aquium olhar homogeneizador, e considerando que em cada local a luta das mulheres assume uma atuação diferenciada a partir da sua conjuntura, é preciso também considerar as contradições que se encontram e fazem da América Latina um local geopoliticamente marcado por uma resistência compartilhada, que é também expressão de uma reivindicação histórica acerca da sua existência e da sua memória.

Com a maré verde, como também em outros movimentos de resistência das mulheres doSul Global, demonstram o sentido da luta e respondem na prática a pergunta que trazemos também no começo deste trabalho “o que éluta?”, como movimento conflitivo de disputa sobre os sentidos políticos, que circundam e determinam a sua vivência em sociedade. Quando propomos investigar ações do movimento feminista latino-americano, reafirmamos também uma resistência que não finda com o movimento aqui evidenciado, ou com uma pauta de luta do movimento feminista, mas reflete atos de resistência que se entrelaçam

A partir das greves de mulheres do/no Sul Global, especialmente Argentina, Chile e Brasil, em que cruzam a violência de gênero com o racismo, machismo e capitalismo, surge uma possibilidade de impulsionar o movimento feminista internacionalmente. Quando as mulheres denunciam em diferentes lugares do mundo que o violador é o Estado $^{10}$, percebe-se que não há como avançar já que o mesmo está a serviço do patriarcado e do capital. Existem alternativas para o modelo que está posto e que surgem especialmente das lutas das mulheres do Sul Global.

As mulheres organizadas no Sul para o Sul Global constroem outras práticas de luta constituindo nova s propostas para a humanidade. É nesse sentido que podemos pensar nas lutas das mulheres como um saber, e como uma proposta para transformar os sistemas políticos, sociais e econômicos que (re)produzem desigualdade e injustiças. Um feminismo

\footnotetext{
${ }^{10}$ Performance de mulheres no Chile em que a música denunciava o Estado como violador.
} 
que articula processos de despatriarcalização e descolonização, em uma luta anticapitalista, que começa no Sul e se internacionaliza.

\section{Referências}

AVELLUTO, Valentina. Gramsci, el movimiento feminista y la crisis de la hegemonía patriarcal. Revista Catarsis. Buenos Aires, ano 1, no 1 , maio de 2019,pp. 27-32.

BALleStrin, Luciana. América Latina e o giro decolonial. Revista Brasileira de Ciência Política. Brasília, no11. maio - agosto de 2013, pp. 89-117.

BALLESTRIN, Luciana. Feminismos Subalternos. Estudos Feministas. Florianópolis, 25(3):530, set-dez, pp. 1035-1054,2017

BBC. Os crimes que Sara Giromini pode ter cometido ao divulgar nome de criança vítima de estupro. G1. Espírito Santo, 17 de agosto de 2020 Disponível em: https://g1.globo.com/es/espirito-santo/noticia/2020/08/17/os-crimes-que-sara-giromini-pode-ter-cometidoao-divulgar-nome-de-crianca-vitima-de-estupro.ghtml. Acesso em: 10 de maio de 2021.

DAVIS, Angela, KLEIN, Naomi. Construindo movimentos [recurso eletrônico]: uma conversa em tempos de pandemia. São Paulo: Boitempo, 2020.

DÍAZ, Estela. Una justa reparación. CTA de los trabajadores. Buenos Aires, 29 de dezembro de 2015. Disponível em: http://www.cta.org.ar/una-justa-reparacion.html. Acesso em: 10 de maio de 2021.

FEDERICI, Silvia. Calibã e a bruxa: mulheres, corpo e acumulação primitiva. São Paulo: Elefante, 2017.

FEDERICI, Silvia. O patriarcado do salário: notas sobre Marx, gênero e feminismo. Volume 1. São Paulo: Boitempo, 2021.

FRASER, Nancy. O feminismo, o capitalismo e a astúcia da história. Mediações. Londrina, v. 14, n.2, p. 11-33, Jul/Dez. 2009

GAGO, Verônica. A potência feminista ou o desejo de transformar tudo. São Paulo: Elefante, 2020.

GOHN, Maria da Glória. Teoria dos Movimentos Sociais: Paradigmas Clássicos e Contemporâneos. São Paulo: Edições Loyola, 1997

GUTIÉRREZ, María Alicia. Marea Verde:la construcción de las luchas feministas. Revista Catarsis. Buenos Aires, ano 1, no 1 , maio de 2019,pp. 33-36.

MARX, Karl; ENGELS, Friedrich. Manifesto do Partido Comunista, 1848. São Paulo: Expressão Popular, 2008.

MIGNOLO, Walter D. Colonialidade: O lado mais escuro da modernidade. Revista Brasileira De Ciências Sociais. Vol. 32, ${ }^{\circ}$ 94, p. 118 , junho/2017.

PARDO, Daniel. O chocante caso de abuso e morte de jovem de 16 anos que provoca indignação na Arge ntina. BBC Mundo. Buenos Aires, 18 de outubro de 2016. Disponível em: https://www.bbc.com/portuguese/internacional-37692722. Acesso em: 10 de maio de 2021.

QUIJANO, Aníbal. A colonialidade do poder: eurocentrismo e América Latina. In: LANDER, Edgardo (org). A colonialidade do saber: eurocentrismo e ciências sociais. Perspectivas latinoamericanas. Colección Sur Sur, CLACSO, Ciudad Autónoma de Buenos Aires, Argentina, p. 107-130,2005.

QUIJANO, Aníbal. Colonialidade do Poder e Classificação Social. in: SANTOS, Boaventura. MENESES, Maria Paula (org). Epistemologias do Sul. Almedina, Coimbra, 2009,p. 73-117.

SAFFIOTI, Heleieth I. B. O poder do macho. São Paulo: Moderna, 1987.

SANTOS, Boaventura de Sousa. Boaventura de Sousa Santos reexamina as formas de lutas. Outras Palavras. 27 de setembro de 2017. Disponível em: https://outraspalavras.net/outrapolitica/boaventura-reexamina-as-formas-de-luta/ acesso em 07 de janeiro de 2021.

SANTOS, Boaventura de Sousa. O fim do império cognitivo: a afirmação das epistemologias do Sul. Belo Horizonte: Autêntica Editora, 2019.

SCIORTINO, Silvana. Consideraciones sobre el movimiento amplio de mujeres a partir del "Ni Una Menos": continuidad histórica, diversidad y trayectorias locales. Publicar en antropología y ciencias sociales. Buenos Aires, ano XVI, $n^{\circ}$ XXIV,julho de 2018 , pp. 27 47.

SEGATO, Rita. Las nuevas formas de la guerra y el cuerpo de las mujeres. Revista Sociedade e Estado - Volume 29 Número 2 Maio/Agosto 2014. Disponível em: https://www.scielo.br/pdf/se/v29n2/03.pdf. Acesso em: 20 de maio de 2021.

SOUZA, Herbert José de (Betinho). Como se faz análise de conjuntura. Petrópolis: Editora Vozes, 2005

VERGÈS, Françoise. Um feminismo decolonial. São Paulo: UBU Editora, 2020. 


\begin{tabular}{ll}
\hline Funções de colaboração exercidas & \\
\hline Livian Lino Netto: & Conceituação; Visualização; Investigação; Escrita (primeira redação); Escrita (revisão e edição); \\
Isadora Ebersol: & Visualização; Investigação; Escrita (primeira redação); Escrita (revisão e edição); \\
Julia Rocha Clasen: & Visualização; Escrita (primeira redação); Escrita (revisão e edição); \\
\hline
\end{tabular}

